\title{
Aspectos jurídicos do bairro rural Portal da Lagoa de Campo Grande, MS, na perspectiva do Desenvolvimento Local
}

\section{Legal aspects of the rural neighborhood Portal da Lagoa of Campo Grande, MS, in the perspective of Local Development}

\author{
Aspectos jurídicos del barrio rural Portal da Lagoa de Campo \\ Grande, MS, en la perspectiva del Desarrollo Local
}

\author{
Bruna Gonçalves Xavier ${ }^{1}$ \\ Rômulo Gustavo de Moraes Ovando ${ }^{2}$ \\ Pedro Pereira Borges ${ }^{3}$
}

${ }^{1}$ Mestranda com bolsa CAPES no Programa de Mestrado e Doutorado em Desenvolvimento Local, da Universidade Católica Dom Bosco (UCDB). Cursando Especialização em Direito Penal e Processo Penal: Corrupção, Crime Organizado e Democracia, na Escola de Direito da Associação dos Membros do Ministério Público (EDAMP). Graduada em Processo Civil pela Universidade Cândido Mendes (UCAM) e em Direito pela UCDB. Coorientadora no Grupo de Pesquisa "Direitos Humanos em Campo Grande e a intersubjetividade em termos de ética e da alteridade: um estudo jurídico-filosófico e educacional" e do Grupo de Pesquisa

"Patrimônio cultural, Direito e Diversidade - UCDB-MS". Advogada. E-mail: bruna_xavier2@hotmail.com, Orcid: http://orcid.org/0000-0002-3937-059X

${ }^{2}$ Mestrando no Programa de Pós-Graduação Mestrado e Doutorado em Desenvolvimento Local, da Universidade Católica Dom Bosco (UCDB). PósGraduado em Direito Médico e Hospitalar e em Direito Civil e Direito Processual

Civil pela Escola Paulista de Direito/SP; Pós-Graduado em Direito do Trabalho e Processo do Trabalho pela Faculdade de Direito Damásio de Jesus. Graduado em Ciências Jurídicas pela UCDB. Membro do Grupo de Pesquisa "Patrimônio Cultural, Direitos e Diversidade". Pesquisador colaborador no Projeto de Pesquisa "A trajetória do mestrado em Desenvolvimento Local - UCDB". Advogado e professor. E-mail: romuloovando@hotmail.com, Orcid: http://orcid.org/0000-0002-1881-2168

${ }^{3}$ Doutor e mestre em Ciências Sociais pela Pontifícia Universidade Católica de São Paulo (PUC/SP). Graduado em Pedagogia pela Universidade Católica Dom Bosco (UCDB), em Teologia pelo Instituto Santo Tomás de Aquino, e em Filosofia pelas Faculdades Unidas Católicas de Mato Grosso (FUCMT). Professor no Programa de Pós-Graduação Mestrado e Doutorado em Desenvolvimento Local da Universidade Católica Dom Bosco (UCDB). E-mail: pobojari@ucdb.br, Orcid: http://orcid.org/0000-0001-9183-5051 
Resumo: Esta pesquisa tem como foco os aspectos jurídicos do bairro rural Portal da Lagoa em Campo Grande, MS, com olhar no desenvolvimento local. O objetivo foi investigar os serviços essenciais que faltam na região e o problema de propriedade, refletindo sobre os impactos que a ausência desses serviços e questões da propriedade podem refletir para o Desenvolvimento Local. A metodologia consistiu em uma pesquisa bibliográfica e observação participante, com entrevistas e rodas de conversas com moradores do bairro. Assim, verificou-se que a população que vive no local enfrenta o sentimento de clandestinidade e abandono, porque falta o domínio dos imóveis, pois só possuem a posse dos lotes e dentre os vários serviços públicos que não são prestigiados na região. Portanto esses fatores podem influenciar significativamente no sentimento de pertença e identidade da população dessa região, fazendo com que seus habitantes vivam em constante sensação de desamparo do Estado e insegurança jurídica.

Palavras-chave: bairro rural; direito de propriedade; serviços públicos; desenvolvimento local.

\begin{abstract}
This research focuses on the legal aspects of the rural neighborhood Portal da Lagoa in Campo Grande, MS, with a focus on local development. The objective was to investigate the essential services lacking in the region and the property problem, reflecting on the impacts that the absence of these services and property issues may reflect for Local Development. The methodology consisted of a bibliographical research and participant observation, with interviews and wheels of conversations with residents of the neighborhood. Thus, it was verified that the population living in the area faces the feeling of clandestinity and abandonment, because they lack the real estate domain, since they only own the lots and among the various public services that are not prestige in the region. Therefore, these factors can significantly influence the sense of belonging and identity of the population of this region, causing them to live in a constant sense of state helplessness and legal insecurity.
\end{abstract}

Keywords: rural district; property right; public services; local development.

Resumen: Esta investigación tiene como foco los aspectos jurídicos del barrio rural Portal da Lagoa en Campo Grande, MS, con mirada en el desarrollo local. El objetivo fue investigar los servicios esenciales que faltan en la región y el problema de propiedad, reflexionando sobre los impactos que la ausencia de esos servicios y cuestiones de la propiedad pueden reflejar para el Desarrollo Local. La metodología consistió en una investigación bibliográfica y observación participante, con entrevistas y ruedas de conversaciones con moradores del barrio. Así, se verificó que la población que vive en el lugar enfrenta el sentimiento de clandestinidad y abandono, porque falta el dominio de los inmuebles, pues sólo poseen la posesión de los lotes y entre los diversos servicios públicos que no son prestigiosos en la región. Por lo tanto, estos factores pueden influir significativamente en el sentimiento de pertenencia e identidad de la población de esa región, haciendo que las mismas vivan en constante sensación de desamparo del Estado e inseguridad jurídica.

Palabras clave: barrio rural; derecho de propiedad; utilidad; desarrollo local. 


\section{INTRODUÇÃO}

Este estudo se justifica por causa da importância da oferta de serviços públicos na vida das pessoas e do prejuízo que a ausência destes pode trazer ao exercício dos direitos fundamentais dos seus habitantes. O presente estudo se concentra, portanto, nos serviços essenciais públicos que não estão sendo oferecidos no bairro rural Portal da Lagoa e também enfoca a questão da posse e propriedade nessas regiões. O bairro em questão encontra-se desprovido de serviços de saúde e de próximos, como estabelece a Lei Orgânica Municipal, além de estar desprovido de infraestrutura essencial para o funcionamento de serviços postais e localização das residências, entre outros.

O objeto de estudo aqui é um bairro que nasceu nas bordas do perímetro urbano de Campo Grande, Mato Grosso do Sul, na década de 1990. A história do bairro foi marcada por situações anormais, segundo a legislação brasileira, sul-mato-grossense e campo-grandense em vigor. Este estudo é de particular interesse porque no epicentro das preocupações está toda uma população que se encontra desassistida em suas necessidades básicas, que são objeto de Direito. No ano de 2018, a questão do bairro foi colocada no âmbito da discussão do Plano Diretor, que está sendo aprovado pela Câmara Municipal de Campo Grande, MS.

Este estudo tem como objetivo investigar sobre os serviços essenciais que faltam na região e a questão do direito de propriedade, sempre à luz do que a legislação prevê nessas hipóteses e refletindo sobre os impactos que a ausência desses serviços e questões da propriedade podem refletir para o Desenvolvimento Local. Como é possível perceber, o suporte deste estudo são as questões relativas aos direitos dos moradores do bairro Portal da Lagoa.

Quanto à metodologia, esta obedeceu a critérios específicos de uma pesquisa correspondente de observação participante, em que foram realizadas entrevistas e rodas de conversa com os moradores do bairro. Foi realizada uma roda de conversas com a participação de vários moradores de região, sendo que esse encontro foi promovido na casa do mestrando Gilberto, sendo possível extrair vários dados para contribuir para com a 
pesquisa. Também foram realizadas entrevistas na região, com perguntas como: Quais os principais serviços que faltam na região? Como é a saúde? Educação? O que você acha que pode melhorar? Além desse aporte, a pesquisa será baseada na legislação em vigor e em bibliografias relativas aos distritos, bairros rurais e ao Plano Diretor do município de Campo Grande.

Este trabalho está dividido em tópicos. Além da introdução, serão também abordados, em tópicos próprios, temas como a história do distrito ou do bairro rural, a história do Bairro Portal da Lagoa, sempre seguindo a perspectiva do direito. Em seguida, será apresentado um levantamento das demandas jurídicas dos habitantes do bairro, como a questão da propriedade, os reflexos da situação dos seus habitantes e as considerações finais.

\section{DISTRITO E O BAIRRO RURAL, NA LEGISLAÇÃO BRASILEIRA}

A relação entre a cidade e o campo é composta por várias especificidades, não apenas geográficas ou sociais, mas também marcada pela aplicação da legislação e seus efeitos em cada um desses cenários. A compreensão e diferenciação do que se entende por rural ou urbano é consideravelmente complexa, ainda mais no atual momento vivido, tendo em vista os rearranjos globais e a influência da tecnologia nas várias áreas da vida cotidiana. Para desvendar essa questão, em um momento inicial, é imprescindível realizar a diferenciação entre os termos "distrito" e "bairro rural", assim como apontar os diplomas normativos que regem esses conceitos.

\subsection{0 distrito}

Institucionalmente o Estado Brasileiro é formado por vários entes, cuja diferenciação subsiste em vista de uma melhor administração dos recursos e do ordenamento de questões territoriais e socais. Entre estes entes, destacam-se os municípios e, dentro dele, os bairros rurais e os distritos. Quanto a distrito, este é conceituado por Pinto (2003, p. 29), como

[...] a menor unidade territorial brasileira com governo próprio, é formada pelo distrito-sede, onde acha-se localizada a cidade, que é a sede municipal e que leva o mesmo nome do município e que corresponde à zona urbana municipal e também pelo território ao seu 
entorno, a zona rural municipal, que pode ser dividida em distritos, cuja maior povoação recebe, geralmente, o nome de vila.

O distrito, portanto, corresponde a uma espécie de subdivisão administrativa do município, a qual pode se dar por diversos motivos, sendo eles de natureza política, administrativa, militar, judicial, fiscal e/ou sanitária, entre outros. Dentre as principais características de um distrito, destaca-se o fato de este possuir uma configuração típica dos espaços urbanos, com serviços públicos que atendem à população da cidade. Os distritos também possuem um liame com o aspecto rural, considerando que as condutas laborativas versam sobre as atividades consideradas como primárias como a agricultura e a pecuária, típicas desse meio ruralista.

Outra característica do distrito é que a sua sede é a vila. Esta possui natureza urbana. Politicamente os distritos não gozam de autonomia administrativa. A administração do distrito é operacionalizada pelo distrito-sede do município ao qual está subordinado. Um distrito pode ser considerado como "embrião do município", caso venha a ser elevado à categoria de município, em uma eventual emancipação político-administrativa (PINTO, 2003).

O distrito possui ainda como característica o modo de vida rural. O aglomerado urbano-rural do distrito, pela simples razão da sua formação e existência, torna-se sujeito de direitos e objeto da preocupação da administração pública municipal, pois este precisa ser contemplado com serviços públicos essenciais, típicos da vida urbana. "A vila é considerada como urbana, pois, no Brasil, a localidade onde existe extensão de serviços públicos é considerada como urbana, e este é o caso das vilas dos distritos" (MONTES; SOARES, 2006, p. 5)

Dessa forma, foi possível observar que os distritos constituem em uma parcela do município, que está subordinada ao município e que por suas características, ainda que cercada de características rurais, é vista como de natureza urbana, em razão do acesso aos serviços públicos.

\subsection{0 bairro rural}

Quanto aos bairros rurais, em alguns Estados brasileiros eles podem ser considerados também como distritos. Como se trata de um conceito 
essencialmente aplicado às cidades, quando se trata dos bairros rurais estes são entendidos como um

[...] agrupamento mais ou menos denso de vizinhança, cujos limites se definem pela participação dos moradores nos festejos religiosos locais. Quer os mais amplos e organizados, geralmente com o apoio na capela consagrada a determinado santo; quer os menos formais promovidos em caráter doméstico. Vemos, assim, que o trabalho e a religião se associam para configurar o âmbito e o funcionamento do grupo de vizinhança, cujas moradias não raro muito afastadas umas das outras, constituem unidade, na medida em que participam no sistema destas atividades. (CANDIDO, 1971, p. 51).

Os bairros, em geral, representam, portanto, agrupamentos com vizinhança e limites definidos. Esses bairros devem ser revestidos de estruturas essenciais. Para Sousa (apud HALLEY, 2014, p. 579), a fisionomia do bairro pode ser produto do sentimento de pertença dos seus moradores. O bairro constitui uma "unidade social impregnada de identidade, valores e diferenciação".

Para Teixeira e Machado (1986) o bairro possui três elementos principais que são determinantes para a sua configuração, isto é, a paisagem urbana, o conteúdo social e a sua função. Quanto ao primeiro elemento, é importante que esse espaço, para ser chamado de bairro, contenha características básicas relacionadas a um tipo, estilo, idade das construções e ruas, entre outras. Em relação ao conteúdo social, este diz respeito ao modo de vida e ao padrão adotado pela população que nele reside. E, por fim, a sua função refere ao fato de ser residencial, comercial e administrativa, entre outras.

O bairro, pelo simples fato de existir, necessita de estruturas consideradas essenciais. A população residente tem direito à pavimentação das vias, energia elétrica, abastecimento de água, coleta seletiva de resíduos, entre outros serviços que contribuam para a vida no local. Para Pacheco (2001, p. 3),

O bairro ou área central de serviços, portanto, deverá ser dotado de estruturas essenciais como vias pavimentadas, energia elétrica e abastecimento de água de qualidade, esgoto, telefonia fixa e móvel, lojas de departamento, bancos, hotéis, serviços de utilidade pública, 
radiodifusão e similar, cinemas e videolocadoras, postos de gasolina, oficinas diversas, supermercados, academias, escritórios, escolas, hospitais ou postos médicos e odontológicos, clínicas médicas e estéticas, farmácias, áreas e equipamentos coletivos de lazer, mercados, feiras, restaurantes, delegacias de policia e de direito do consumidor, e amplo poder reivindicatório da população. Corresponderia à estrutura de uma pequena a média cidade, caso se encontrasse regionalmente disperso.

Quando o bairro é rural, este é considerado como muito além do simples território onde está localizado. Os bairros rurais se diferenciam dos urbanos em razão de que carregam características de atividades de primeiro setor (agricultura, pecuária, entre outros), enquanto os segundos são dotados de serviços públicos considerados essenciais. Os bairros rurais se caracterizam por um modo de vida rudimentar e destoante do espaço urbano, inclusive com ausência de vários serviços considerados como essenciais. Queiroz (1973 apud HALLEY, 2014, p. 579) define bairro rural como

Aquele cujos membros, estando à frente de empreendimentos rurais de que guardam responsabilidade (mesmo quando não conservam a totalidade da colheita), desenvolvem entre si relações de trabalho expressas na ajuda mútua, e conservam relações de vizinhança que se concretizam na participação, em nível social igualitário das atividades cotidianos e festivas do grupo de localidade.

Dessa forma, os bairros rurais se caracterizam por um modo de vida mais rudimentar, ainda que estejam circundados pela zona urbana, mas demonstra características de vida do setor primário e a ausência dos serviços públicos. A seguir, será voltado o olhar para a questão da legislação nesse âmbito.

\subsection{Enfoque jurídico}

Bairros rurais e/ou distritos são dois entes existentes dentro de um município. Eles são, ao mesmo tempo, sujeitos de direito e objeto das preocupações das administrações municipais. Pela Constituição Federal de 1988, os municípios são entes independentes. Segundo o Art. 1ํa a República Federativa é constituída pelos entes denominados de União, 
Estados, Municípios e o Distrito Federal. O Art. 18 estabelece, no seu caput, que, quanto à organização político-administrativa, estes entes são todos autônomos, nos termos da Constituição Federal de 1988.

No que diz respeito aos distritos e subdistritos, em 12 de setembro de 1996 foi publicada a Emenda Constitucional n. 15, cujo conteúdo versava sobre a criação, a incorporação, a fusão e o desmembramento de Municípios. Esta deve ser feita por lei estadual. Uma das regras para se proceder à criação desses entes é a da viabilidade municipal, apresentada e publicada na forma da lei. Essa norma se refere precipuamente à criação de um novo município.

Quanto aos distritos e/ou bairros rurais, estes dependem, no entanto, de lei estadual. No caso das aglomerações urbanas, para ser considerado como um centro urbano, um local deve ter, segundo a Lei Complementar n. 1, de 1967, 200 casas. É dentro desta realidade que se possibilita a criação de distritos. Essa lei foi modificada pela Lei Complementar n. 46, de 26 de agosto de 1984.

A diferenciação entre o que é urbano e rural é muito importante para fixar os critérios legais que cercam esses ambientes. A legislação que trata do perímetro urbano de um munícipio, geralmente define o que é a zona urbana e o que é a zona rural do território, surgindo uma espécie de demarcação.

De igual modo, quanto aos distritos, os requisitos para a sua criação se dão por intermédio de uma lei estadual. Os municípios, dessa forma, não podem a qualquer custo criar novos distritos, fazendo necessário que um povoado siga as determinações legais para, somente a partir disso, o município, após aprovado pela Câmara de Vereadores, elevar uma determinada região à categoria distrital. Nesse sentido, destaca-se que

O Decreto-Lei 311/38 havia exigido a delimitação dos quadros urbano e suburbano das sedes municipais e distritais, conferindo ao Conselho Nacional de Geografia a atribuição de estabelecer os requisitos mínimos para a elaboração dos mapas. A uniformização pretendida foi alcançada, mediante cumprimento bastante criterioso dessas normas, para as quais o prazo estabelecido era inadiável. Foi com esses atos, baixados por prefeitos num período em que não funcionavam as Câmaras Municipais, que se consagrou a figura legal do Perímetro 
Urbano. Mas a autonomia conferida aos Estados no período pós-1946 resultou em adoção de critérios variáveis e diversas interpretações sobre o que deveria ser o perímetro urbano. (BERNARDES; SANTOS; WALCACER, 1983, p. 47).

A Lei Federal n. 6.766, de 1979, trata sobre o parcelamento do solo urbano e suas providências, estabelecendo que "o parcelamento do solo só poderá ocorrer em área urbana, de expansão urbana ou urbanização específica". Além disso, o Art. 53 estabelece que todas as alterações concernentes ao uso do solo rural, com vistas às finalidades urbanas, serão precedidas por audiência no Instituto Nacional de Colonização e Reforma Agrária (INCRA) e da Prefeitura municipal, sempre seguindo o que determina a lei.

De acordo com a Lei Federal n. 6.766, os parcelamentos localizados nas zonas habitacionais devem contar com pelo menos vias de circulação, escoamento de águas pluviais, abastecimento de água potável e saneamento básico, além do fornecimento de energia elétrica. A competência para legislar sobre essas áreas é do município, ou seja, esse ente será o responsável por dispor as normas para a ocupação e o uso em cada localidade abrangida por sua competência legislativa (BRASIL, 1979).

No município de Campo Grande, no estado de Mato Grosso do Sul, a Lei Complementar n. 74, de 6 de setembro de 2005, estabeleceu os critérios para o ordenamento do uso e da ocupação do solo no respectivo município. De acordo com o artigo 4ํㅡㄹ inciso VIII, dessa Lei, os bairros são definidos como "áreas pertencentes à Regiões Urbanas organizadas para qualificar as condições de trabalho, circulação, recreação, moradia e as relações de cooperação em todos os tipos de atividades de vizinhança".

O Inciso XLV estabelece que o loteamento, compreendido como uma subdivisão de uma gleba de lotes que tem como finalidade a edificação, deve ser beneficiado com a abertura de novas vias de circulação, ou prolongamento destas, modificações ou ampliações. O inciso LXXXV, do Art. 4으, estabelece que a zona urbana corresponde a uma parte do município que tem como característica básica as edificações contínuas e a existência de aparatos sociais com finalidade urbana basilar, como o direito a habitar, trabalhar, recreação e a circulação, tendo no mínimo duas redes de abastecimento de água, saneamento básico, serviço de iluminação pública, 
escolas, postos de saúde a uma distância máxima de três quilômetros do local de habitação do cidadão.

A mesma Lei Complementar também dispõe que a área rural corresponde a uma área municipal que não é considerada urbana, com o uso predominante de atividades "agropecuária, agroindustriais, extrativista, silvicultura e conservação ambiental” (CAMPO GRANDE, 2005). Os critérios para a administração desses locais devem ser estabelecidos pelo município. Portanto considera-se como distinção entre os bairros urbanos e rurais e os distritos o fato de que a área rural é dotada de características do setor primário, inclusive com a ausência dos requisitos formais de existência de uma infraestrutura básica, assim como dos serviços públicos essenciais nessa região.

No tópico a seguir, o enfoque adotado voltará o olhar para um bairro de Campo Grande, que está situado nas bordas do perímetro urbano do município, que tem entre suas características a insegurança jurídica e anseia por ser incluído no perímetro urbano do município.

\section{BAIRRO RURAL PORTAL DA LAGOA NAS BORDAS DO PERÍMETRO URBANO DE CAMPO GRANDE, MS}

O bairro rural Portal da Lagoa foi fruto de um empreendimento lançado em meados do ano de 1997 como "Condomínio Portal da Lagoa" pela empresa "Correta Empreendimentos Imobiliários". Quando do lançamento e início da edificação do "condomínio", restou constatado que o local do empreendimento situava-se além do perímetro urbano, ou seja, não era considerado como parte integrante da cidade de Campo Grande, conforme as ilustrações 1 e 2 . 
Aspectos jurídicos do bairro rural Portal da Lagoa de Campo Grande, MS, na perspectiva do desenvolvimento local

Ilustração 1- Planta baixa do Bairro Rural Portal da Lagoa

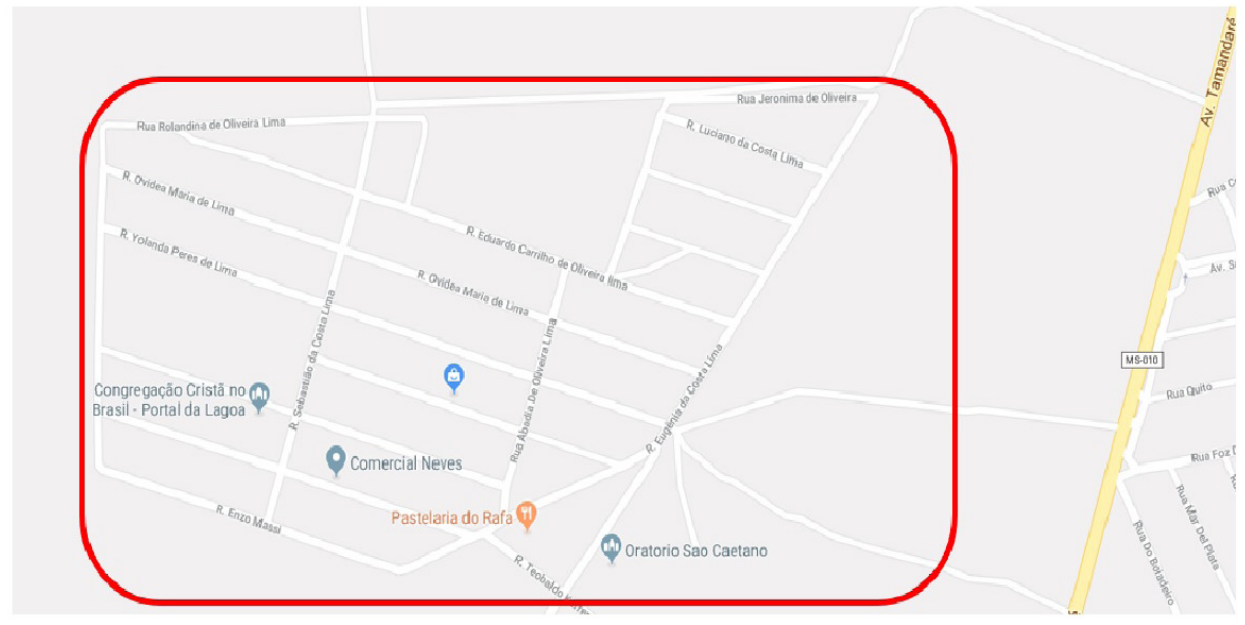

Fonte: Elaboração própria a partir do Google Maps (2018).

Ilustracão 2 - Bairro Portal da Lagoa

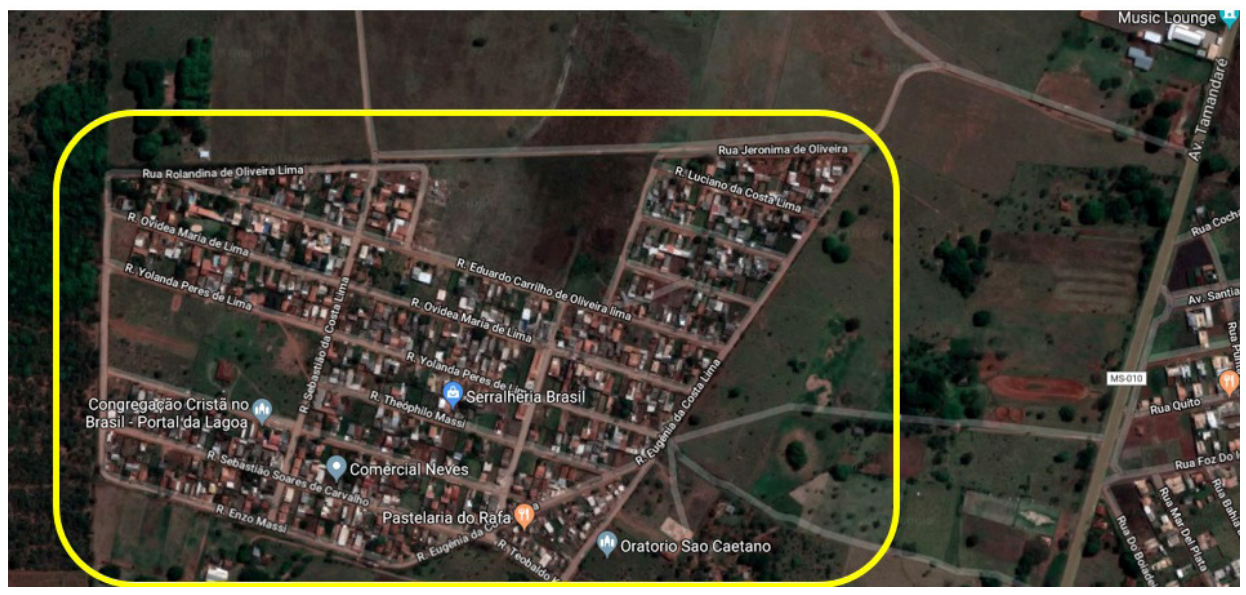

Fonte: Google Mapas (2018). 
Ilustraçao 3 - Bairro Portal da Lagoa, fora do perímetro urbano de Campo Grande

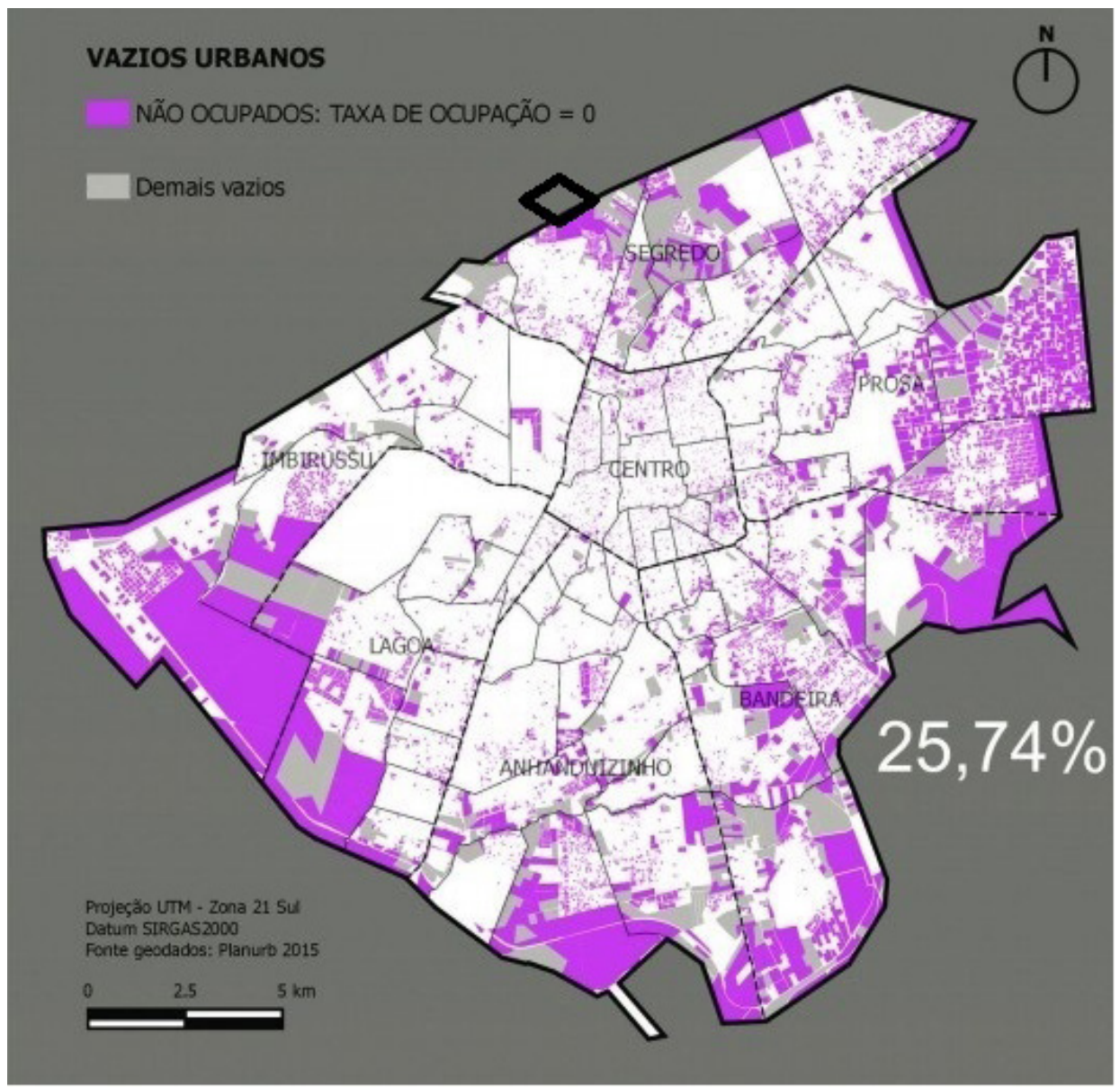

Fonte: Elaboração própria a partir do Mapa do Plano Diretor de Campo Grande (2018).

O Plano Diretor da cidade, que foi aprovado no ano de 1995 e colocado em prática sob a égide da Lei de Ordenamento do Uso e da Ocupação do Solo (Lei n. 2.567, de 1988), não foi levado em consideração pela empresa. Quanto ao Plano diretor, a Constituição Federal de 1988 outorga aos municípios o dever de estimular o princípio da função social da propriedade e delimitar a fiscalização das áreas subutilizadas, submetendo-as à divisão ou edificação compulsórias, ou até mesmo à desapropriação com o respectivo 
pagamento de títulos e cobrança do Imposto Predial e Territorial Urbano (IPTU) progressivo no tempo.

O empreendimento imobiliário do Portal da Lagoa não foi aprovado nem obteve o registro de averbação no órgão competente. Em princípio foi classificado como um empreendimento de natureza urbana, porém situado além do perímetro urbano. Isto fez com que o núcleo urbano passasse a ser considerado como área rural. Daí o fato de ser denominado Bairro Rural Portal da Lagoa. Por ser considerado um loteamento informal por ausência de observância da legislação, a empresa responsável não efetuou devidamente a delimitação do condomínio e sequer criou meios de acesso a este, além de não ter provido os serviços essenciais, dentre eles os relacionados ao fornecimento de água e saneamento, bem como os de energia elétrica, os quais são imprescindíveis para sua aprovação pelo ente municipal.

O Bairro Rural Portal da Lagoa está situado na zona norte de Campo Grande, na região do Segredo. Seus lotes não correspondem à dimensão prevista para o macrozoneamento dessa região. A Imobiliária, no entanto, efetuou a venda dos lotes a terceiros, tendo, inclusive, celebrado contratos de compra e venda de tais lotes com aproximadamente 400 cidadãos interessados.

Aos poucos os já residentes do empreendimento imobiliário foram inserindo alguns serviços essenciais, os quais, em tese, deveriam ser de responsabilidade do Poder Público. A água passou a ser fornecida por intermédio de um poço artesiano e retirada por meio de bomba elétrica, garantindo, assim, de maneira precária, o mínimo necessário para a sobrevivência daqueles que lá se encontravam instalados.

As adversidades suportadas pelos moradores originários são principalmente de ordem jurídica. Com os lotes não legalizados, os moradores passaram a não arcar com o pagamento das mensalidades e muitos deles passaram a ser considerados como invasores dos lotes. Outras consequências de natureza local são que o bairro não é provido de serviço postal do Correios. O bairro, situado na borda urbana de Campo Grande, não possui nome de ruas e Código de Endereçamento Postal (CEP), e a iluminação pública é extremamente precária. As correspondências são encaminhadas 
ao bairro vizinho, São Caetano. Muitos dos moradores desse bairro cobram taxa dos moradores do bairro vizinho pelo serviço prestado.

Os moradores do Bairro Rural Portal da Lagoa não contam ainda com serviços essenciais de coleta de lixo, pavimentação asfáltica, sistema de drenagem de águas, unidades básicas de saúde, creches, escolas, saneamento básico, praças, segurança pública, transporte público e distribuição de medicamentos, dentre outros. A falta desses serviços públicos essenciais fere frontalmente o princípio constitucional da dignidade da pessoa humana, tendo em vista que vários direitos sociais assegurados na Constituição Federal de 1988 não estão sendo oferecidos na região. Os moradores do Condomínio Portal da Lagoa não possuem também escritura de seus bens e tampouco são contribuintes do IPTU, tendo em vista que, por se tratar de um empreendimento imobiliário que se encontra além do perímetro urbano da cidade, é considerado uma área rural.

Esta situação transformou o bairro em um bairro clandestino. A clandestinidade do bairro despertou a atração de ocupantes de parcos recursos, especificamente aqueles que foram "excluídos" para a periferia e não tinham condições de sobreviver com a locação de um imóvel, encontrando, dessa forma, uma oportunidade de se estabelecerem sem a imposição de quaisquer ônus. Por conseguinte, não demorou muito para haver edificações de barracos e moradias precárias, sendo que essa situação ocasionou inúmeros problemas sociais, dentre eles o tráfico de drogas, prostituição e a prática de outros crimes de gravidades distintas.

A insegurança e a ausência de previsibilidade de regularização do empreendimento geraram nos moradores o sentimento de clandestinidade e abandono, visto terem eles ciência de que a qualquer momento podem perder o único bem material que possuem. Isto faz com que o sentimento de identidade territorial, produzido em relação ao grupo e ao lugar vivido, seja definido muito mais por relações afetivas e culturais do que por seus limites (BONNEMAISON, 2002 apud LE BOURLEGAT, 2011, p. 114).

No dia 24 de agosto de 2015, foi realizada uma entrevista, de responsabilidade do Jornal Top Mídia News (2015), com uma suposta moradora que alegou, à época, ter sido a "desbravadora" do condomínio, tendo esse processo de ocupação iniciado no ano de 2000. O cenário dessas ocupações 
Aspectos jurídicos do bairro rural Portal da Lagoa de Campo Grande, MS, na perspectiva do desenvolvimento local

não é animador, pois a precariedade das edificações é extrema, pois não é garantido ao ser humano o mínimo necessário para uma moradia digna, conforme é possível verificar das fotografias abaixo colacionadas:

Ilustração 4 - Situação das ruas e das residências do Portal da Lagoa
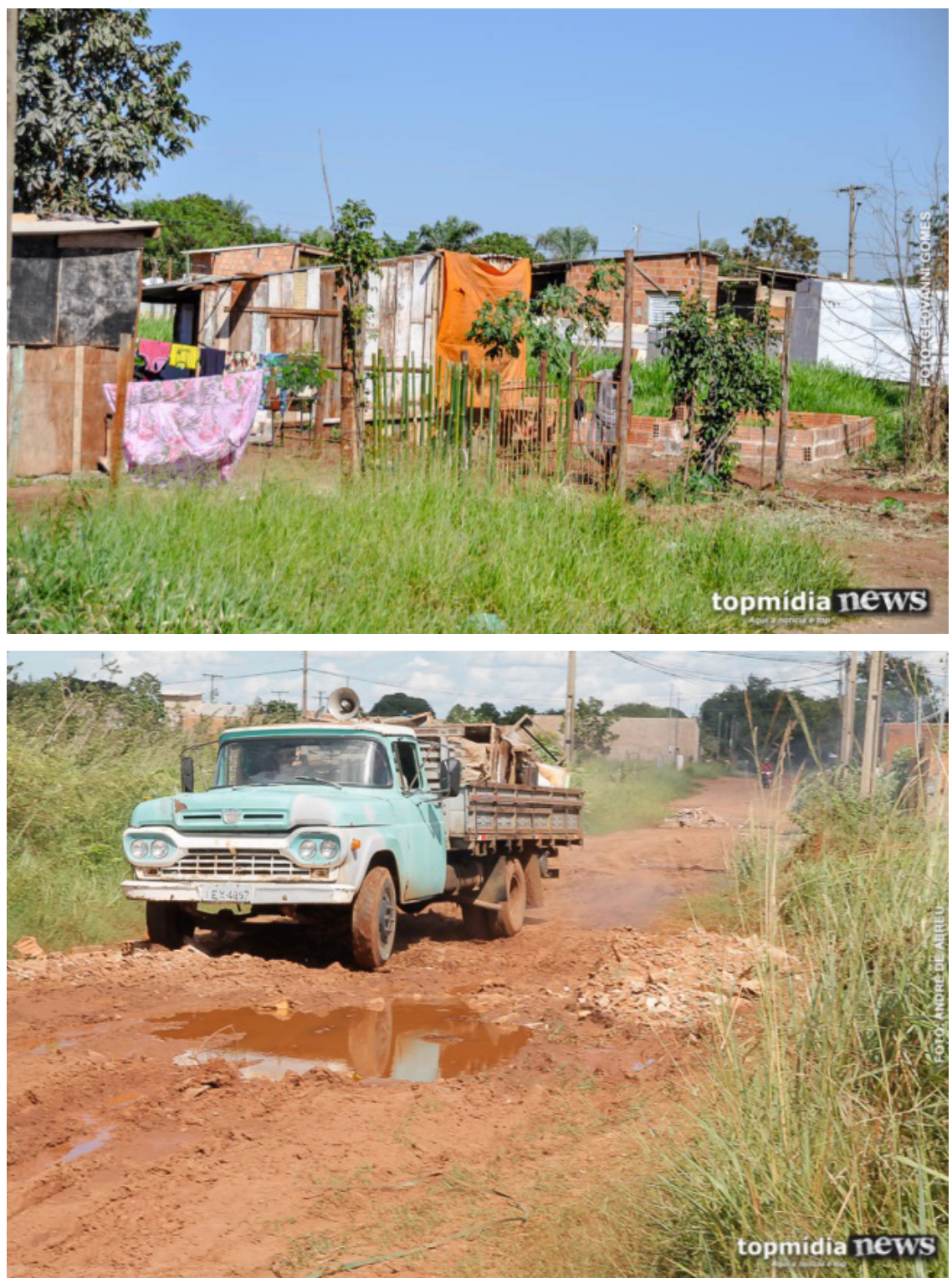

Fonte: Top Mídia News (2015). 
Já no que se refere ao número de ocupantes do bairro Portal da Lagoa, de acordo com informações concedidas pelos próprios moradores ao Jornal Campo Grande News (2016), no ano de 2017, já computavam aproximadamente 700 famílias estabelecidas. Apesar da debilidade demonstrada, o maior imbróglio tem sido com relação aos moradores que adquiriram os lotes de boa-fé e para tanto arcaram rigorosamente com os seus respectivos pagamentos. Alguns investiram nos bens realizando benfeitorias e até mesmo edificaram suas próprias residências, as quais podem ser consideradas de qualidade e dignas de moradia. Além disso, é possível constatar no bairro a existência de comércios e serviços, dentre os quais destacam-se conveniências, bares, igrejas, mercados, salões de beleza e pizzarias, entre outros.

O bairro conta com atividade econômica informal, ou seja, muitos moradores não possuem vínculo empregatício registrado em suas Carteiras de Trabalho e Previdência Social (CTPS), atuando como verdadeiros profissionais autônomos (vendedores ambulantes, diaristas, eletricistas, encanadores, piscineiros, pedreiros, serventes em geral e chapas, dentre outros).

A situação do Bairro Rural Portal da Lagoa é precária e, cada vez mais, vem se tornando insustentável, haja vista que não há previsão para que aquele seja incluído no plano diretor da cidade e consequentemente faça parte de seu perímetro urbano. No âmbito jurídico, há uma ação civil pública proposta pelo Ministério Público do Estado de Mato Grosso do Sul contra a empresa Correta e o Município de Campo Grande, a fim de que ambos sejam condenados a regularizar a situação do bairro. Referida ação está tramitando no Poder Judiciário Sul-Mato-Grossense desde o fim do ano de 2010 e atualmente encontra-se pendente do julgamento de recurso no Superior Tribunal de Justiça.

\section{ASPECTOS GERAIS E JURÍDICOS DO BAIRRO PORTAL DA LAGOA}

No ano de 2018, foi promovido um estudo in loco no Bairro Portal da Lagoa, em Campo Grande, como parte de um estudo sobre o entorno da Universidade Católica Dom Bosco (UCDB). No ano de 2018, com as mudanças promovidas para a aprovação do novo Plano Diretor do município, o bairro foi inserido no território urbano municipal. A ilustração 2 apresenta a 
Aspectos jurídicos do bairro rural Portal da Lagoa de Campo Grande, MS, na perspectiva do desenvolvimento local

situação geral do bairro rural Portal da Lagoa. Nela podem ser encontrados os aspectos positivos e os negativos, bem como as oportunidades que o bairro tem para se alavancar, a partir do momento em que se tornar parte do perímetro urbano de Campo Grande.

\subsection{Aspectos gerais do bairro}

O bairro rural Portal da Lagoa é um bairro que tem características próprias. Em razão disso, sua situação pode ser considerada como sui generis. Ele está nas bordas do perímetro urbano e não recebeu, ao longo dos seus mais de 20 anos de existência, os benefícios que um distrito ou um bairro urbano ou rural deveria receber pelo simples fato de neles residirem cidadãos que pagam impostos e são sujeitos de serviços públicos. O bairro possui uma vida própria, com pequenas iniciativas de comércio local, de promoção da visibilidade dele, como um pequeno parque pessoal que foi construído no seu perímetro. Além disso, conta com pessoas que desenvolvem atividades econômicas em vista da própria sustentação familiar, como a venda de produtos e a oferta de serviços variados, em especial na área da construção civil.

O foco deste artigo, no entanto, é a questão jurídica, pois o bairro ainda enfrenta a questão da propriedade dos lotes, devido a um fator histórico da venda dos lotes pela Correta Imobiliária, nos finais da década de 1990. Daí surge a questão da propriedade dos lotes do bairro, pois os moradores somente têm a posse. Esse problema se deu em razão de que houve um loteamento clandestino realizado na região e, por conta disso, existe esse impasse que também impede a realização dos serviços públicos essenciais.

O loteamento não foi dividido de acordo com a normativa do Parcelamento Rural (suas unidades não possuem tamanho mínimo exigido - módulo rural), além de não possuir atividades rurais propriamente ditas (extrativa, pecuária, agrária ou agroindustrial). A característica do bairro é, portanto, de anomalia, pois o loteamento não foi considerado nem como bairro urbano nem como bairro rural ou distrito pelo ente público do município de Campo Grande. A ilustração a seguir evidencia as principais forças e oportunidades presentes nesse bairro, bem como as fraquezas e ameaças evidenciadas pelos moradores do local, em pesquisa realizada. 
Ilustração 5- Situação do bairro rural Portal da Lagoa
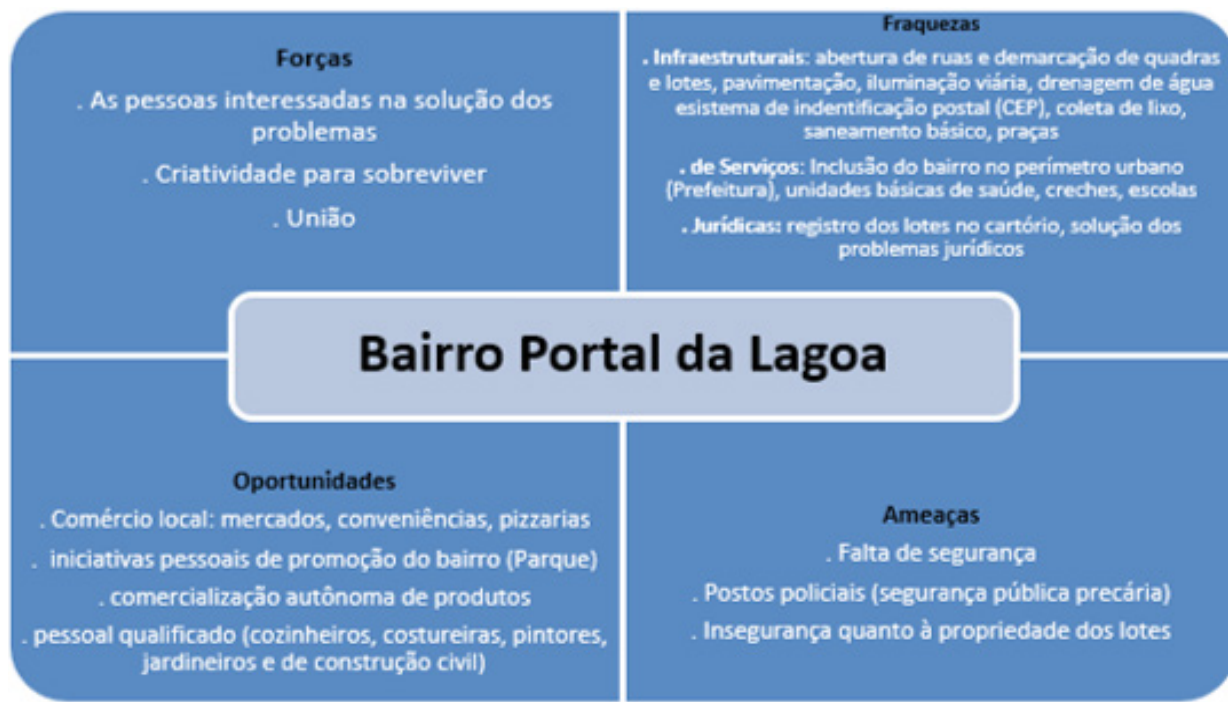

\section{Bairro Portal da Lagoa}

Fonte: Elaboração dos autores (2018).

Dessa forma, o bairro Portal da Lagoa não pôde ser considerado Condomínio ou Incorporação, conforme previsão do CC/2002 e da Lei n. 4.591/1964, visto que não atendeu aos requisitos da incorporação imobiliária e os lotes foram vendidos sem edificações e sem os serviços essenciais de um bairro urbano ou rural. Em razão disso, o bairro foi embargado por meio de uma ação civil pública por ser irregular o parcelamento de imóvel rural como finalidade residencial e/ou comercial.

É desses fatos que decorrem a insegurança jurídica e a ausência de serviços públicos essenciais de infraestrutura e de serviços. Estes são ofertados de maneira bastante deficiente, de forma que os cidadãos nele residentes só sentem a presença do poder público municipal quando a situação do bairro se apresenta de maneira assaz precária.

\subsection{Aspectos jurídicos do bairro rural Portal da Lagoa}

Quanto à questão jurídica, os problemas mais latentes do bairro são a questão da propriedade, da posse e da tributação. Junto com esses problemas seguem-se outros, como o da segurança pública, do saneamento básico, 
Aspectos jurídicos do bairro rural Portal da Lagoa de Campo Grande, MS, na perspectiva do desenvolvimento local

da saúde, da educação, do transporte e de infraestrutura de modo geral.

De acordo com o que se revelou na pesquisa e entrevista realizada com os moradores, vários serviços públicos não estão presentes no bairro, bem como os que estão se demonstram de modo precário. Dentre eles, ressalta-se a ausência de postos de saúde e escolas naquela localidade, sendo que os cidadãos procuraram em outros locais, com distâncias superiores a 3 km, bem como a pavimentação é precária e falta saneamento básico, razão pela qual utilizam fossas, recurso esse que é muito prejudicial para a saúde.

Nesse sentido, considerando a ausência desses serviços públicos tidos como essenciais, ressalta-se o teor do Art. 60, da Constituição Federal de 1988, que prevê que "São direitos sociais a educação, a saúde, o trabalho, a moradia, o lazer, a segurança, a previdência social, a proteção à maternidade e à infância, a assistência aos desamparados, na forma desta Constituição" (BRASIL, 1988).

Sob esse enfoque, destaca-se que os direitos apontados se revelam como direitos fundamentais de segunda dimensão, os quais precisam ser reafirmados pelo Estado a fim de se garantir o mínimo existencial para as pessoas, bem como de forma que se estabeleça o princípio da dignidade humana. Sobre o mínimo existencial, Torres (1989) o considera como sendo a garantia de condições mínimas de existência humana digna que devem ser respeitadas pelo Estado, sob um viés essencial e inalienável.

De igual forma, a dignidade da pessoa está assentada na legislação brasileira como um dos objetivos do Estado e detentora de vários direitos fundamentais humanos, tanto no que concerne às prestações positivas, quanto sobre as negativas (abstenções). Para Piovesan (2003, p. 188),

[...] todo ser humano tem uma dignidade que lhe é inerente, sendo incondicionada, não dependendo de qualquer outro critério, senão ser humano. O valor da dignidade humana se projeta, assim, por todo o sistema internacional de proteção. Todos os tratados internacionais, ainda que assumam a roupagem do Positivismo Jurídico, incorporam o valor da dignidade humana.

Vários desses direitos sociais fundamentais não estão sendo garantidos no bairro Portal da Lagoa, de modo que as pessoas se sentem desamparadas. Seus moradores são considerados como cidadãos anômalos. A instabilida- 
de gera o sentimento de clandestinidade e abandono dessas pessoas. "O sentimento de identidade territorial, produzido em relação ao grupo e ao lugar vivido é definido muito mais por relações afetivas e culturais do que por seus limites" (BONNEMAISON, 2002 apud LE BOURLEGAT, 2011, p. 114).

Nesse enfoque, a principal questão que atormenta a população que reside nesse bairro é quanto à propriedade dos lotes, tendo em vista que só possuem a posse dos imóveis. Inicialmente para esclarecer essa questão, é importante diferenciar a posse e a propriedade. A posse não é um direito real, ou seja, não decorre da coisa, assim, quem a detém não pode alienar ou realizar outras condutas que sejam inerentes a quem possui o domínio do bem. O Art. 1196, do Código Civil, esclarece que "considera-se possuidor todo aquele que tem de fato o exercício, pleno ou não, de algum dos poderes inerentes à propriedade". Por outro lado, a propriedade é um direito real, sendo decorrente do bem, considerando proprietário aquele que "tem a faculdade de usar, gozar e dispor da coisa e o direito de reavê-la do poder de quem quer que injustamente a possua ou detenha", conforme preceitua o Art. 1228, do Código Civil, de 2002.

O problema surgiu em razão de que os lotes do bairro foram vendidos em forma de condomínio, mas esses não seguiam as normas de condomínio ou incorporação previstos no Código Civil e na Lei 4.591, de 1964, em razão de que não se enquadraram como uma incorporação imobiliária, e os lotes foram vendidos sem que houvesse edificações. Além disso, ressalta-se que aquele não foi dividido consoante normativa do Parcelamento Rural, pois suas unidades não possuem tamanho mínimo exigido (módulo rural), além de que não há exploração e atividades rurais (extrativa, pecuária, agrária ou agroindustrial), assim como a região encontra-se em situação de anomalia, pois passou mais de 20 anos de existência fora do perímetro urbano municipal.

Por todos esses fatores, o empreendimento foi embargado por meio de uma ação civil pública por ser irregular o parcelamento de imóvel rural como finalidade residencial e/ou comercial. Por não haver a regularização da área, os responsáveis foram condenados em primeira instância, em 2016, a obter a aprovação do condomínio na esfera administrativa; para isso terão que construir toda a estrutura que se fizer necessária e entregar aos pro- 
prietários a documentação de cada imóvel vendido, sob pena de multa para cada contrato a cada mês de atraso. Para que os responsáveis cumpram o teor dessa decisão, terão um prazo de três anos, contados a partir da data da publicação da lei que determinar a área como urbana (Plano Diretor) que atualmente está em edição pelo município de Campo Grande. A ilustração 3 sintetiza algumas normas aplicadas à situação jurídica do bairro, conforme anteriormente relatado:

Ilustração 6- Normas jurídicas sobre a situação legal do bairro Portal da Lagoa

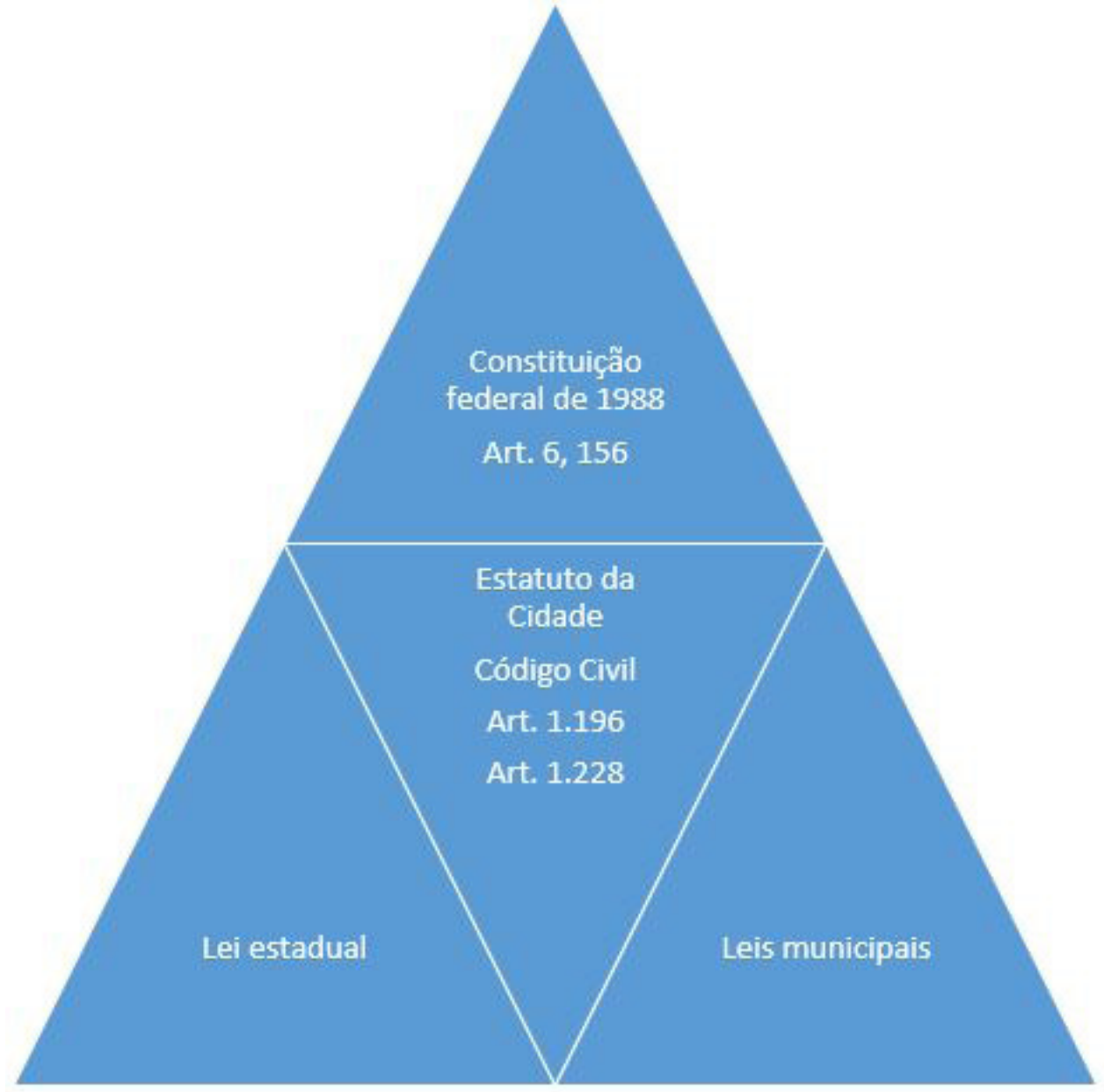

Fonte: Elaboração própria dos autores (2018). 
De igual maneira, essa insegurança jurídica não gera problemas apenas para os moradores, mas também para poder público no recolhido dos tributos. O Imposto Predial e Territorial Urbano (IPTU), por exemplo, de competência dos Municípios (CF/1988, Art. 156, Inc. I), possui como hipótese de incidência a propriedade, o domínio útil ou a posse de bem imóvel localizado em zona urbana municipal, assim como o ITR (Imposto sobre a Propriedade Territorial Rural) é um tributo de competência da União (CF/1988, Art. 153, Inc. VI), que tem como hipótese de incidência a propriedade, o domínio útil ou a posse de bem imóvel rural. Por se tratar de área não regulamentada pelo Município, não caracterizada como "urbana" ou "rural", não há incidência desses tributos.

Dessa forma, constata-se que a ausência desses recursos na região, bem como a questão da insegurança jurídica quanto à propriedade dos imóveis, podem deixar a população do bairro exposta a inúmeros riscos, como a ausência de um posto de saúde na região, a falta de escolas, que faz com que as crianças tenham que se deslocar até longas regiões, e outros malefícios não apenas para esse bairro rural, mas para toda a comunidade, pela falta de possibilidade do recolhimento de tributos que poderiam ser revertidos para a oferta dos serviços públicos essenciais.

\section{CONSIDERAÇÕES FINAIS}

O Portal da Lagoa se classifica, no momento, como um bairro rural, tendo em vista que existem muitas limitações jurídicas em relação ao bairro, fazendo com se caracterize como uma situação sui generis, ou anômala, em razão de que não pode ser considerado um bairro urbano, bem como também não é um distrito, pois Ihe faltam algumas características fundamentais. Além disso, o bairro não foi inserido no perímetro urbano do município. Dessa forma, o local passou a ser considerado como rural. De qualquer forma, o bairro não foi atendido nem pelo ente público municipal nem contou com a assistência da imobiliária que iniciou o empreendimento.

Considerando todos esses problemas, a população que vive no local enfrenta o sentimento de clandestinidade e abandono, pois Ihes falta a escritura e documentação dos imóveis, tendo em vista que só possuem a 
Aspectos jurídicos do bairro rural Portal da Lagoa de Campo Grande, MS, na perspectiva do desenvolvimento local

posse e não a propriedade dos lotes, bem como dentre os vários serviços públicos que não são prestigiados na região.

Dessa forma, verifica-se que esses fatores podem influenciar de modo significativo ao sentimento de pertença e identidade da população dessa região, fazendo com que esta viva em constante sensação de desamparo do poder público e insegurança jurídica. Em outros termos, são cidadãos anômalos vivendo em situação anômala em todos os sentidos de sua existência.

\section{REFERÊNCIAS}

BERNARDES, Lysia Maria C.; SANTOS, Sergio Roberto L.; WALCACER, Fernando C. Redefinição do conceito de urbano e rural. Curitiba: Ipardes, 1983.

BRASIL. Lei 10.406, de 10 de janeiro de 2002. Institui o Código Civil. Brasília, DF: Senado Federal, 2002.

BRASIL. Constituição da República Federativa do Brasil (1988). Brasília, DF: Senado Federal, 1988.

BRASIL. Lei n. 6.766, de 19 de dezembro de 1979. Dispõe sobre o Parcelamento do Solo Urbano e dá outras Providências. Disponível em: http://www.planalto.gov. br/ccivil_03/leis/l6766.htm

BRASIL. Lei n. 4.591, de 16 de dezembro de 1964. Dispõe sobre o condomínio em edificações e as incorporações imobiliárias. Disponível em: http://www.planalto. gov.br/ccivil_03/leis/14591.htm

CAMPO GRANDE, Mato Grosso do Sul. Lei Complementar n. 74, de 2005. Dispõe sobre o ordenamento do uso e da ocupação do solo no município de campo grande e dá outras providências. Disponível em: http://www.campogrande.ms.gov.br/ planurb/downloads/lei-complementar-n-742005/

CAMPO GRANDE NEWS. Clandestino, bairro tem prazo para "virar" cidade ou ser demolido. 2016. Disponível em: https://www.campograndenews.com.br/cidades/ capital/clandestino-bairro-tem-prazo-para-virar-cidade-ou-ser-demolido. Acesso em: 18 nov. 2018.

CANDIDO, Antonio. Os parceiros do Rio Bonito: estudo sobre o caipira paulista e a transformação dos seus meios de vida. Rio de Janeiro: Livraria Duas Cidades, 1971. 
HALLEY, Bruno Maia. Bairro rural/bairro urbano: uma revisão conceitual. GEOUSP - Espaço e Tempo, São Paulo, v. 18, n. 3, p. 577-93, set./dez. 2014.

LE BOURLEGAT, Cleonice A. Desenvolvimento local na abordagem territorial do atual sistema-mundo. In: TREMBLAY, Gaetan; VIEIRA, Paulo Freire (Org.). O papel da universidade do desenvolvimento local: experiências brasileiras e canadenses. Florianópolis: APED/SECCO, 2011. p. 107-122.

MONTES, Silma Rabelo; SOARES, Beatriz Ribeiro. O distrito como unidade de organização do território rural e urbano: o exemplo de Tapuirama (Uberlândia MG). In: ENCONTRO DE GRUPOS DE PESQUISA, 2., Uberlândia, 2006. Disponível em: http://w3.ufsm.br/engrup/iiengrup/pdf/t33.pdf. Acesso em: 4 set. 2018.

PACHECO, João Batista. O conceito geográfico de bairro: uma aplicação à questão do Sítio Campinas/Basa e da Ilhinha. Revista de Políticas Públicas, São Luís, MA, v. 5, n. $1 / 2,2001$.

PINTO, Georges José. Do sonho à realidade: Córrego Fundo - MG: fragmentação territorial e criação de municípios de pequeno porte. 2003. 248 f. Dissertação (Mestrado em Geografia) - Instituto de Geografia, Universidade Federal de Uberlândia, Uberlândia, 2003.

PIOVESAN, Flávia. Direitos humanos e princípio da dignidade da pessoa humana. In: LEITE, George Salomão (Org.). Dos princípios constitucionais: considerações em torno das normas principiológicas da Constituição. São Paulo: Malheiros, 2003.

TEIXEIRA, Marlene P. V.; MACHADO, Rosa Maria. Conceito de bairro - unidade popular ou técnica? Anuário do Instituto de Geociências- UFRJ, Rio de Janeiro, 1986. Disponível em: http://www.anuario.igeo.ufrj.br/anuario_1986/vol_10_66_71.pdf. Acesso em: 14 set. 2018.

TOPMÍDIA NEWS. A desbravadora da ocupação Portal da Lagoa. 2015. Disponível em: http://www.topmidianews.com.br/especiais/a-desbravadora-da-ocupacaoportal-da-lagoa/32434/. Acesso em: 18 nov. 2018

TORRES, Ricardo Lobo. O mínimo existencial e os direitos fundamentais. Revista de Direito Administrativo, Rio de Janeiro, v. 177, p. 29-49, jul. 1989. Disponível em: http://bibliotecadigital.fgv.br/ojs/index.php/rda/article/view/46113 